\title{
The Effects of Whole-body Vibration on the Gross Motor Function, Balance, and Gait of Children with Cerebral Palsy
}

\author{
Dong-Baek Son ${ }^{1}$, Kyoung-Bo Lee ${ }^{1}$, Byong-Yong, Hwang ${ }^{* 2}$ \\ 'Dept. of Physical Therapy, St. Vincent Hospital \\ ${ }^{*}$ Dept. of Physical Therapy, College of Health \& Welfare, Yong-In University
}

\begin{abstract}
Purpose The aim of this study was to determine the effect of Whole-Body Vibration on gross motor function and balance, gait of children with cerebral palsy. Methods The Design is ABA design of single-subject experimental design. This study participate 2 subjects for 7 years old who were diagnosed children with spastic cerebral palsy. Baseline(A) and Baseline(A') phases were received not WBV, Intervention(B) phase provided with 30 minutes WBV in 10 session. All subjects were measured with the Gross Motor Function Measure(GMFM-66), Pediatric Balance Scale(PBS), One leg standing, Gait analysis in session and at follow-up. Results The results showed that the subjects increased GMFM-66 score and remained in the assessment after the intervention. But the subject 2 was decrease again after baseline(A'). PBS of both subjects increased until after intervention but decreased during baseline(A'). In the one leg standing, both subjects increased after the baseline(A). Especially, the sessions exceeding the two standard deviation in the intervention process were 5 times and 8 times, respectively. The gait symmetry index of both subjects increased after intervention. Conclusion WBV was effective in improving gross motor and balance, gait in children with cerebral palsy.
\end{abstract}

Key words Whole-Body Vibration, Cerebral Palsy, Gross Motor Function, Balance, Gait

Corresponding author Byong-Yong Hwang (bobathkorea@naver.com)
Received date
21 January 2019
Revised date
31 January 2019
Accepted date
12 February 2019

\section{Introduction}

Cerebral palsy is a non-progressive disease accompanied by difficulties in movement and postural control. ${ }^{1)}$ Activity is compromised by poor movement and postural development, as well as problems with sensation, perception, behavior, and secondary musculoskeletal development. ${ }^{2)}$ Cerebral palsy is one of the most common causes of physical impairment in childhood. ${ }^{3)}$ Such children exhibit higher-level sensory impairments and muscle tension than do their peers. They find it difficult to control their muscles, compromising the ability to exercise. ${ }^{4)}$ Several researchers have found that muscle strength in such children is related to motor function. 5),6),7) Various physical therapies improve latent motor ability and ameliorate the secondary problems. ${ }^{8)}$ The interventions include task-oriented exercises, ${ }^{9}$ progressive resistance ex-

http:dx.doi.org/10.17817/2019.01.31.111370 ercises ${ }^{10)}$ virtual reality training, ${ }^{11)}$ treadmill work, weight-training machines (tilting tables), ${ }^{12)}$ and whole-body vibration (WBV). ${ }^{3), 13), 14), 15)}$ Saquetto et al. (2015) found that WBV was associated with functional improvements in children with cerebral palsy, enhancing flexibility, posture control, balance, and coordination. ${ }^{16)}$ WBV is a form of neuromuscular training that uses vibration to stimulate points critical in terms of balance maintenance (thus, points exhibiting vibration reflexes; abbreviated TVRs). ${ }^{17)}$ When vibrations of a floor are transmitted throughout the body, these vibrations stimulate both the spine and the appendages, transmitting contraction commands to the spinal cord, enhancing muscle response rates and aiding movement by activating the nervous system. In addition, many exercises seek to mobilize (excite) the Golgi tendon organ. ${ }^{18)}$ Although many studies have explored the effects of whole-body vibration on subjects with various conditions, few works on children with cerebral palsy have appeared; it is difficult to de- 
Table 1. General characteristics of the subjects

\begin{tabular}{ccccccc} 
Subject & Gender & $\begin{array}{c}\text { Age } \\
\text { (years) }\end{array}$ & $\begin{array}{c}\text { Weight } \\
(\mathrm{kg})\end{array}$ & $\begin{array}{c}\text { Height } \\
\text { (cm) }\end{array}$ & $\begin{array}{c}\text { GMFCS } \\
\text { Diagnosis }\end{array}$ \\
\hline 1 & Male & 7 & 33 & 127 & Rt. hemipleia & 1 \\
2 & Male & 7 & 27 & 122 & Diplegia & 1 \\
\hline
\end{tabular}

termine if the initial effects persist. Here, we suggest that whole-body vibration benefits children with cerebral palsy. We sought to improve function using an appropriate intervention.

\section{Materials and Methods}

\section{Subjects}

We studied two children diagnosed with cerebral palsy in S hospital of Suwon City, Gyeonggi-do, South Korea; both were undergoing rehabilitation. Their parents gave written informed consent. The general characteristics of the subjects are in Table 1 . The study period ran from March 5, 2018 to May 30, 2018, thus for about 3 months.

\section{Methods}

(1) Procedure and intervention

We used the single-subject, ABA research design. Baseline (phase A) and later phase (phase A') data were each collected 5 times in the absence of vibration; interventional (phase B) data were collected 10 times. The whole-body vibrator was a Galileo Med-S model (Novotec Medical GmbH, Pforzheim, Germany) delivering alternating sinusoidal oscillations at $1-27 \mathrm{~Hz}$ at an amplitude of $0 \pm 3.9 \mathrm{~mm}$. Both subjects bent their knees by about $30^{\circ}$ when on the footboard and bent their hips and ankles slightly with the feet about $20 \mathrm{~cm}$ apart. Vibration was applied in blocks of 6 min (two 3-min sessions with a rest of 1-2 min between sessions; five sequences in total over 30 min). Over the sessions, the vibrational frequency was gradually increased by $0.5 \mathrm{~Hz}$ (within the range 11-18 $\mathrm{Hz}$ ) as tolerated by the children, who wore waist belts to protect against falls. If a child complained of fatigue or dizziness, exercise was immediately paused for $1-2 \mathrm{~min}$.

\section{Measurements}

(1) Gross Motor Function

We used a Gross Motor Function Measure (the GMFM-66) appropriate for children with cerebral palsy aged 0-18 years. The five assessment panels feature 66 items, thus fewer than the GMFM-88; scores can be obtained without evaluating all items. In addition, responses are ranked in terms of difficulty; functional ability is readily assessed. ${ }^{19)}$ The scores for each item ranged from 0 (failure) to 3 (complete success); the test-retest reliability was $0.99 .^{20)}$ In other studies, the test-retest reliability was 0.97 and the interlaboratory reliability $0.98 .^{21)}$ All scores were estimated using Gross Motor Ability Estimator (GMAE) software and were calculated at baseline, before, and twice after intervention (four assessments in all).

\section{(2) Balance}

The Pediatric Balance Scale (PBS) was used to analyze changes in balance. The 14 items of the revised Berg Balance Scale include the time taken to maintain

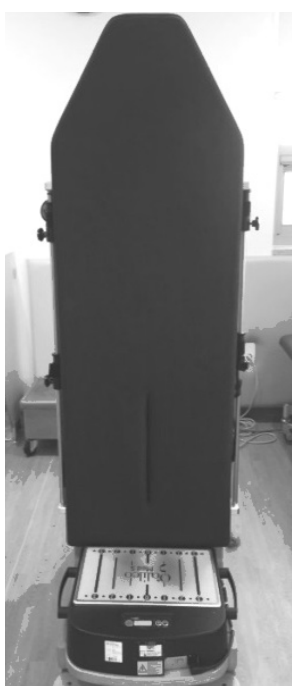

Figure 1. Galileo Med S 
a sitting posture, the quality of the posture per se, and the ability to maintain head posture for $30 \mathrm{~s}$ (less than the time of the original Scale). Each test was attempted up to three times; the scores ranged from 0 to 4 and four assessments were conducted (as described above). The attributes required to stably perform independent activities at school, at home, and in the community include competence in terms of balance when sitting, writing, stretching, turning, and climbing stairs. The intra-rater and inter-rater correlation coefficients attained $0.99 .^{22}$ Also, the maximum duration of one-leg standing on the more affected side was measured ${ }^{23)}$; this is an important measure of postural control. ${ }^{24)}$

\section{(3) Gait}

A G-sensor (BTS Bioengineering S.p.A., Milan, Italy) was used to measure walking/gait parameters and shaking. Walking cadence, average speed, walking period, and the walking and standing positions were measured by reference to changes in the center-of-gravity (at the L4-5 level) accelerations on the $\mathrm{x}-, \quad \mathrm{y}-$, and $\mathrm{z}$-axes, using an accelerometer and a gyroscope. All data were analyzed using G-studio software. ${ }^{25)}$ We also evaluated walking symmetry by representing leg accelerations during gait as curves ${ }^{26}$; we compared the two curves using the following formula.

Symmetric Index $=\{(\operatorname{corr} \dagger+1) \times 100\} / 2$

$\dagger$ corr : cross correlation coefficient of the parameter

Complete overlap of the two curves corresponds to a score of 100. The children walked back and forth for $8 \mathrm{~m}$ at a natural speed ${ }^{27)}$; four assessments were performed (as described above).

\section{Statistics analysis}

The baseline and test data are presented as graphs

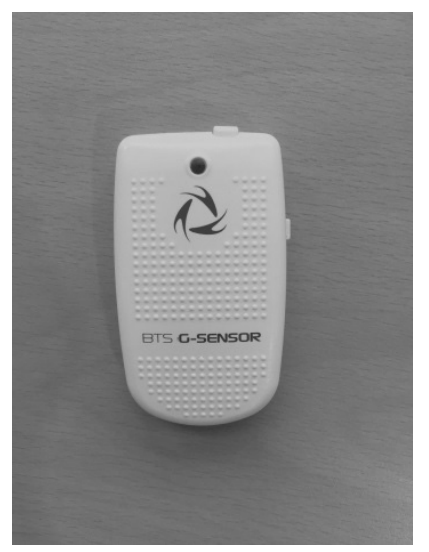

Figure 2. G-SENSOR

with descriptive statistics; averages (with two standard deviations) were compared between the baseline and test periods. Our analyses of changes afforded by intervention were thus sensitive. ${ }^{28)}$ Any data that lay outside the mean \pm two standard deviations was considered significant. ${ }^{29)}$

\section{Results}

\section{Gross Motor Function}

The major outcomes are listed in Table 2. The initial baseline score of subject 1 was $82.99 \%$, and this was maintained at the pre-test assessment. After 10 whole-body vibration exercises, the score improved to $86.52 \%$ and was maintained after the post-test. The initial baseline score of subject 2 was $77.46 \%$ and was maintained at the pre-test. After intervention, the score increased to $78.82 \%$, but decreased after the post-test.

\section{Balance}

The baseline PBS score of subject 1 was 47 and was maintained on the pre-test assessment. After 10 interventions, the score improved to 53 , but fell to 50 after post-test. The baseline PBS score of subject 2 was 47 and was maintained on the pre-test assessment. After

Table 2. Variations of GMFM-66

\begin{tabular}{ccccc} 
& baseline 1 & Pre-test & Post-test & baseline 2 \\
\hline Subject 1 & 82.99 & 82.99 & 86.52 & 86.52 \\
Subject 2 & 77.46 & 77.46 & 78.28 & 75.34 \\
\hline
\end{tabular}


Table 3. Variations of PBS

\begin{tabular}{ccccc} 
& baseline 1 & Pre-test & Post-test & baseline 2 \\
\hline Subject 1 & 47 & 47 & 53 & 50 \\
Subject 2 & 47 & 47 & 51 & 50 \\
\hline
\end{tabular}

Table 4. Variations of one leg standing

(unit: second)

\begin{tabular}{cccc} 
& Baseline A & Intervention B & Baseline A' \\
\hline Subject 1 & $1.83 \pm 0.35$ & $2.49 \pm 0.15$ & $2.62 \pm 0.08$ \\
Subject 2 & $1.69 \pm 0.25$ & $2.43 \pm 0.22$ & $2.57 \pm 0.06$ \\
\hline
\end{tabular}

Table 5. Variations of symmetry index

\begin{tabular}{ccccc} 
& baseline 1 & Pre-test & Post-test & baseline 2 \\
Subject 1 & 81.3 & 83 & 86.9 & 89.5 \\
Subject 2 & 92.7 & 94 & 98.5 & 99.3 \\
\hline
\end{tabular}

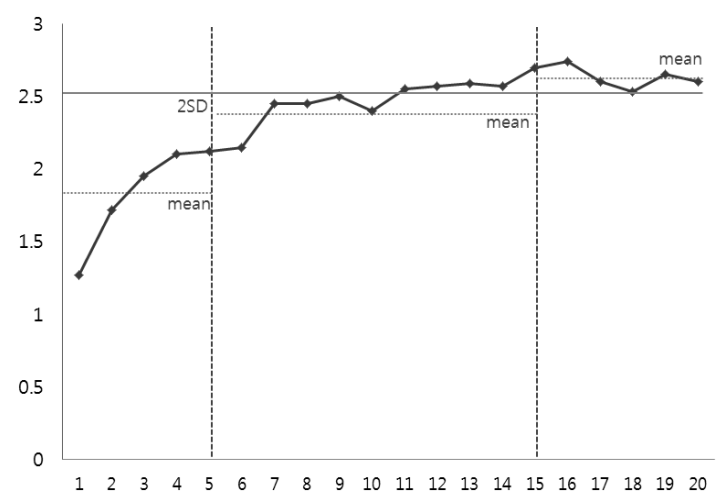

$\mathrm{M} \pm \mathrm{SD}$ : mean \pm standard deviation

Figure 3. Change of one leg standing in session(subject 1

intervention, the score improved to 51 , but, after the post-test, decreased to 50 .

The baseline one-leg-standing time of subject 1 was $1.83 \pm 0.35 \mathrm{~s}$, and that after intervention B $2.49 \pm$ $0.15 \mathrm{~s}$; the later phase A' score increased to $2.62 \pm$ 0.08 s. During intervention, the scores on 5 of 10 sessions exceeded the baseline mean \pm two standard deviation. The baseline one-leg-standing time of subject 2 was $1.69 \pm 0.25 \mathrm{~s}$, which rose to $2.43 \pm 0.22 \mathrm{~s}$ during intervention, and then to $2.57 \pm 0.06 \mathrm{~s}$ during follow-up. During intervention, the scores of 8 of 10 sessions exceeded the baseline value \pm two standard deviations.

\section{Gait}

The symmetry index of subject 1 increased from $83 \%$ prior to whole-body vibration to $86.9 \%$ after intervention and to $89.5 \%$ after the post-test. The symmetry index of subject 2 increased from $94 \%$ before intervention to $98.5 \%$ after intervention and $99.3 \%$ after the post-test.

\section{Discussion}

Whole-body vibration exercises have been used to treat various diseases and have been effective in children with cerebral palsy. ${ }^{15), 30) .31), 32)}$ Here, we inves- 
tigated the effect of such exercises on the gross motor function, balance, and gait of two children with cerebral palsy. A gross motor function measure (GMFM) is often used to assess functional activity in such children. ${ }^{15,31), 33), 34)}$ Ibrahim et al. (2014) reported significant improvements in the GMFM D and E domains of a whole-body vibration group (both $\mathrm{p}<0.05$ ). Our results suggest that such exercise may improve sensory function and exercise performance. We used the GMFM-66 to assess motor function. For subject 1, the score of $82.99 \%$ pre- test improved to $86.52 \%$ after intervention and was maintained after the post-test. Thus, whole-body vibration transmitted through the feet when standing may stimulate the senses and induce muscle contractions, improving and maintaining function. ${ }^{14)}$ For subject 2, the score of $77.46 \%$ pre-test increased slightly to $78.28 \%$ after intervention, but then decreased to $75.34 \%$ after the post-test. In relation to the foregoing Cheng (2015) showed that the duration of any effect was as short as 3 days, and the systematic review of Novak (2013) revealed a universal therapeutic effect for children with cerebral palsy, although analysis was difficult. ${ }^{35)}$ In addition, the feelings and general condition of children during assessment may compromise cooperation.

Children with cerebral palsy lack stability and balance because of muscle weakness, abnormal muscle tension, and difficulties in exercising. ${ }^{36)}$ Kown et al. (2011) reported that the equilibrium of such children was 41.7 PBS points prior to horse-riding but 45.8 points after riding $(\mathrm{p}=0.004){ }^{37)}$ Ahlborg et al. (2006) found that 8 weeks of whole-body vibration training for children with cerebral palsy significantly improved both dynamic balance and vestibular function. ${ }^{13)}$ Here, we assessed balance using the one- way PBS. In subject 1, 6 points of improvement were evident after intervention, but balance decreased after the post-test. In subject 2, an improvement of 4 points was evident after intervention, but, again, a decrease was apparent after the post-test. During intervention, the PBS scores increased, attributable to symmetrical weight support via uniform crossover vibration, and improvements in lower-limb sensation and strength. However, the score reductions evident after the post-test suggest that any effect of stimulation may be short term. ${ }^{38,39)}$ In particular, there has been a report that difficulty may arise due to the low degree of control ankle joint contributing to balance ability. ${ }^{40), 411}$

One leg standing improved after 5 of 10 sessions for subject 1 , and after 8 of 10 sessions for subject 2 . Liao et al. (2001) suggested that one-step tests usefully evaluated and predicted postural stability. ${ }^{42}$ Whole-body vibration improved adjustments in various directions, and postural stability (especially when moving). The walking ability of children with cerebral palsy is the area most in need of attention. Lee \& Chon (2013) reported significant improvement in walking speed, walking cycle, and ankle angle when whole-body vibration was used to improve the ability to control the lower extremities. ${ }^{30)}$ Here, we evaluated left-/right-side differences using a symmetry index to quantify the extent to which the curves of the two sides were similar; leg accelerations during gait were represented as curves. The pre-test score of subject 1 was $83 \%$, which became $86.9 \%$ after intervention and $89.5 \%$ after the post-test. For subject 2, the figures were 94\%, 98.5\%, and 99.3\%; little difference was evident between the right and left sides. Body-weight shifting and the ability to symmetrically support weight by the anterior and posterior lower limb regions directly affect functional gait and improve after whole-body vibrational training. ${ }^{15), 31)}$ We also found that pre-postural training induced active weight- shifting and improved postural control and walking ability. In addition, muscle weakness may limit anti-gravity motion and activity, ${ }^{43)}$ but whole-body vibration exercise may help improve function.

The limitations of our study include the fact that it is difficult to generalize our results because of the small numbers of participants and interventions and absence of control group; it was also difficult to control for variables that might affect our results. In addition, subject enthusiasm (in terms of participation), concentration, and emotional and physical commitments were all poor. 


\section{Conclusion}

We explored the effects of whole-body vibration on the gross motor function, balance, and gait of two children with cerebral palsy (thus exhibiting hemiplegia and bilateral paralysis) using an ABA study design. The initial score of subject 1 was $82.99 \%$, which improved to $86.52 \%$ after intervention, and then remained unchanged. The initial score of subject 2 was $77.46 \%$, which increased to $78.82 \%$ after intervention, but then decreased after the post-test. The initial PBS score of subject 1 was 47 and improved to 53 after intervention, but then decreased to 50. The initial PBS score of subject 2 was 47 and improved to 51 after intervention, but then decreased to 50 after the post-test. In the one-leg-standing test, the baseline A value was $1.83 \pm 0.35 \mathrm{~s}$, and the intervention $\mathrm{B}$ value $2.49 \pm 0.15 \mathrm{~s}$. The later phase $\mathrm{A}^{\prime}$ increased to 2.62 $\pm 0.08 \mathrm{~s}$. In addition, during intervention, the scores of 5 of 10 sessions exceeded the mean \pm two standard deviations of the baseline value. The baseline A one-leg-stand time was $1.69 \pm 0.25 \mathrm{~s}$, the interventional value $2.43 \pm 0.22 \mathrm{~s}$, and the post-test value 2.57 $\pm 0.06 \mathrm{~s}$ (thus slightly greater). During intervention, the scores of 8 out of 10 intervention sessions exceeded the baseline value \pm two standard deviations. For subject 1, gait symmetry index increased from $83 \%$ prior to intervention to $86.9 \%$ after intervention and $89.5 \%$ after the post-test; the figures for subject 2 were 94, 98.5, and 99.3\%, respectively. Our work suggests that long-term interventional studies with many more subjects are needed.

\section{References}

1. Yin Foo R, Guppy M, Johnston LM. Intelligence assessments for children with cerebral palsy: A systematic review. Developmental Medicine \& Child Neurology. 2013;55:811-818.

2. Rosenbaum P, Paneth N, Leviton A, et al. A report: The definition and classification of cerebral palsy April 2006. Dvelopmental Medicine \& Child Neurology. 2007;109, 8-14.

3. Ruck J, Chabot G, Rauch, F. Vibration treatment in cerebral palsy: A randomized controlled pilot study. The Journal of Musculoskeletal and Neuronal Interactions. 2010;10:77-83.

4. Krigger KW. Cerebral palsy: An overview. American Family Physician. 2006;73(1), 91-100.

5. Ross SM, MacDonald M, Bigouette JP. Effects of strength training on mobility in adults with cerebral palsy: a systematic review. Disability and health journal, 9(3), 2016;375-384.

6. Dallmeijer AJ, Rameckers EA, Houdijk H, et al. Isometric muscle strength and mobility capacity in children with cerebral palsy. Disability and rehabilitation. 2017;39(2), 135-142

7. van Vulpen LF, de Groot S, Rameckers E, et al. Improved Walking Capacity and Muscle Strength After Functional Power-Training in Young Children With Cerebral Palsy. Neurorehabilitation and neural repair. 2017;31(9), 827-841.

8. C. Stark, P. Herkenrath, H. Hollmann, et al. Early vibration assisted physiotherapy in toddlers with cerebral palsy - a randomized controlled pilot trial. J Musculoskelet Neuronal Interact. 2016;16(3):183-192

9. Damiano DL, Stanley CJ, Ohlrich L, et al. Task-specific and functional effects of speed-focused elliptical or motor-assisted cycle training in children with bilateral cerebral palsy: randomized clinical trial. Neurorehabilitation and neural repair. 2017;31(8),736-745.

10. Bania TA, Dodd KJ, Baker RJ, et al. The effects of progressive resistance training on daily physical activity in young people with cerebral palsy: a randomised controlled trial. Disability and rehabilitation. 2016;38(7), 620-626.

11. Ravi DK, Kumar N, Singhi P. Effectiveness of virtual reality rehabilitation for children and adolescents with cerebral palsy: an updated evidence-based systematic review. Physiotherapy. 2017;103(3), 245-258.

12. Franki I, Desloovere K, De Cat J, et al. The evidence-base for basic physical therapy techniques targeting lower limb function in children with cerebral palsy: a systematic review using the International Classification of Functioning, Disability and Health as a conceptual framework. J Rehabil Med. 2012; 44:385-95.

13. Ahlborg L, Andersson C, Julin P. Whole-body vibration training compared with resistance training: effect on spasticity, muscle strength and motor performance in 
adults with cerebral palsy. Journal of rehabilitation medicine,. 2006;38(5), 302-308.

14. El-Shamy SM. Effect of whole-body vibration on muscle strength and balance in diplegic cerebral palsy: a randomized controlled trial. American journal of physical medicine \& rehabilitation. 2014;93(2), 114-121.

15. Ko MS, Sim YJ, Kim DH, et al. Effects of three weeks of whole-body vibration training on joint-position sense, balance, and gait in children with cerebral palsy: A randomized controlled study. Physiotherapy Canada. 2016;68(2), 99-105.

16. Dickin DC, McClain MA, Hubble RP, et al. Changes in postural sway frequency and complexity in altered sensory environments following whole body vibrations. Human movement science. 2012;31(5), 1238-1246.

17. Saquetto M, Carvalho V, Silva C, et al. The effects of whole body vibration on mobility and balance in children with cerebral palsy: a systematic review with meta-analysis. J Musculoskelet Neuronal Interact .2015;15:137-144.

18. Cardinale M, Bosco C. The use of vibration as an exercise intervention. Exercise and sport sciences reviews. 2003;31(1), 3-7.

19. Alotaibi M, Long T, Kennedy, et al. The efficacy of GMFM-88 and GMFM-66 to detect changes in gross motor function in children with cerebral palsy $(\mathrm{CP})$ : A literature review. Disabil. Rehabil. 2014;36(8), 617-627.

20. Russell DJ, Avery LM, Rosenbaum PL. Improved scaling of the Gross Motor Function Measure for children with cerebral palsy: Evidence of reliability and validity. Phys Ther. 2000;80, 873-85.

21. Wei S, Su-Juan W, Yuan-Gui L, et al. Reliability and validity of the GMFM-66 in 0-to 3-year-old children with cerebral palsy. American journal of physical medicine \& rehabilitation. 2006;85(2), 141-147.

22. Franjoine MR, Gunther JS, Taylor MJ. Pediatric balance scale: a modified version of the berg balance scale for the school-age child with mild to moderate motor impairment. Pediatr Phys Ther. 2003;15:114-28.

23. Drusini AG, Eleazer GP, Caiazzo M, et al. One-leg standing balance and functional status in an elderly community-dwelling population in northeast Italy. Aging Clin Exp Res, 2002, 14: 42-46.

24. Shimada H, Uchiyama Y, Kakurai S. Specific effects of balance and gait exercises on physical function among the frail elderly. Clin Rehabil, 2003,17: 472-479.

25. Lim SY, Lee BJ, Lee WH. Receiver operating characteristic curve analysis of the timed up and go test as a predictive tool for fall risk in persons with stroke: a retrospective study. Physical Therapy Rehabilitation Science 2018;7:54-60

26. Yoon SK, Kang SH. Effects of inclined treadmill walking training with rhythmic auditory stimulation on balance and gait in stroke patients. Journal of physical therapy science. 2016;28(12), 3367-3370.

27. Pau M, Leban B, Collu G, et al. Effect of light and vigorous physical activity on balance and gait of older adults. Archives of gerontology and geriatrics. 2014;59(3), 568-573.

28. Nourbakhsh MR, Ottenbacher KJ. The statistical analysis of single-subject data: a comparative examination.Physicaltherapy. 1994;74(8),768-776.

29. Gottman JM, Leiblum SR. How to do psychotherapy and how to evaluate it: A manual for beginners. Holt,Rinehart \& Winston. 1974.

30. Lee B, Chon S. Effect of whole body vibration training on mobility in children with cerebral palsy: a randomized controlled experimenter-blinded study. Clin Rehab. 2013;27(7):599-607.

31. Ibrahim MM, Eid MA, Moawd SA. Effect of whole-body vibration on muscle strength, spasticity, and motor performance in spastic diplegic cerebral palsy children. Egyptian Journal of Medical Human Genetics. 2014;15(2),173-179.

32. Cheng HYK, Ju YY, Chen CL, et al. Effects of whole body vibration on spasticity and lower extremity function in children with cerebral palsy. Human movement science. 2015;39, 65-72

33. Brien M, Sveistrup $H$. An intensive virtual reality program improves functional balance and mobility of adolescents with cerebral palsy. Pediatr Phys Ther 2011; 23: 258-66.

34. Dodd KJ, Taylor NF, Graham HK. A randomized clinical trial of strength training in young people with cerebral palsy. Developmental medicine and child neurology. 2003;45(10), 652-657.

35. Novak I, Mcintyre S, Morgan C, et al. A systematic review of interventions for children with cerebral palsy: state of the evidence. Developmental Medicine \& Child Neurology. 2013;55(10),885-910. 
36. Shumway-Cook A, Woollacott MH. Normal Postural Control. In: Motor Control: Translating Research Into Clinical Practice, 4th edn. Baltimore, MD: Lippincott Williams \& Wilkins, 2012: 161-94.

37. Kwon JY, Chang HJ, Lee JY, et al. Effects of hippotherapy on gait parameters in children with bilateral spastic cerebral palsy. Arch Phys Med Rehab 2011; 92: 774-9.

38. Broekmans T, Roelants M, Alders G, et al. Exploring the effects of a 20-week whole-body vibration training programme on leg muscle performance and function in persons with multiple sclerosis. Journal of Rehabilitation Medicine. 2010;42(9), 866-872.

39. Ruck J, Chabot G, Rauch F. Vibration treatment in cerebral palsy: A randomized controlled pilot study. J Musculoskelet Neuronal Interact. 2010;10(1), 77-83.

40. Pozo-Cruz BD, Adsuar JC, Parraca JA, et al. Using whole-body vibration training in patients affected with common neurological diseases: a systematic literature review. The of Alternative and Complementary Medicine. 2012;18(1),29-41.
41. Jeon SJ, Hwang BY, Lee KB, et al. Comparison of Foot Pressure Distribution and Balance Between Children with Cerebral Palsy and Normal Children. J Korean Soc Neur Ther.2015;19(3):1-7.

42. Liao HF, Mao PJ, Hwang AW. Test-retest reliability of balance tests in children with cerebral palsy. Developmental medicine and child neurology. 2001;43(3), 180-186.

43. Lee EJ. The Effects of Sling Exercise Based with Bobath Concept on the Balance of Spastic Diplegia Cerebral Palsy: Case Report. J Korean Soc Neur Ther.2018;22(3):11-18. 